\title{
Yonga Levha Üretiminde Motorlu Testere Talaşı Kullanımının Bazı Levha Özelliklerine Etkisi
}

\author{
Abdullah İSTEK ${ }^{1 *}$, Sıddık ÇELİK $^{1}$, İsmail ÖZLÜSOYLU ${ }^{1}$ \\ ${ }^{1}$ Bartın Üniversitesi, Orman Fakültesi, Orman Endüstri Mühendisliği Bölümü,74100, BARTIN
}

Öz

Bu çalışmada motorlu testere ile ağaç kesiminde oluşan talaşların yonga levha üretimine uygunluğu ve levha özelliklerine etkisi araştırılmıştır. Hammadde olarak sahil çamı, kayın ve dişbudak odunlarından elde edilen motorlu testere talaşı (MTT) ile endüstriyel odun yongaları (EY) kullanılmıştır. Deney levhaları üre formaldehit tutkalı ile 3 tabaklı olarak üretilmiştir. Elde edilen levhaların fiziksel ve mekanik özellikleri standart yonga levha özellikleriyle karşılaştırılarak, motorlu testere talaşının yonga levha üretimine uygunluğu belirlenmiştir. Elde edilen sonuçlara göre MTT yongalarının yonga levha üretiminde kullanılabileceği, fiziksel ve mekanik özelliklerin genel amaçlı kullanımlara uygun olduğu değerlendirilmiştir. Deney levhaların mekanik özelliklerinden en yüksek yüzeye dik çekme direnci (IB) $0,51 \mathrm{~N} / \mathrm{mm}^{2}$ ile EY kontrol levha grubunda, en yüksek eğilme direnci (BS) $12.84 \mathrm{~N} / \mathrm{mm}^{2}$ olarak MTT kontrol grubu levhalarında elde edilmiştir.

Anahtar Kelimeler: Motorlu testere talaşı, üre formaldehit tutkalı, yonga levha, fiziksel ve mekanik özellikler.

\section{Effect of Chainsaw Chips Use on Some Panel Properties in Particleboard Production}

\begin{abstract}
In this study, the feasibility of using chainsaw dust in particleboard production was investigated. Chainsaw dust chips were used as raw material, obtained from the maritime pine (Pinus pinaster), beech (Fagus orientalis) and ash (Fraxinus excelsior) woods. Test boards were produced with three layers with urea formaldehyde resin. The physical and mechanical properties of the boards produced were compared with standard particleboard values and the suitability of chainsaw dust for particleboard production was determined. The results indicate that the highest internal bond strength was observed in the industrial chip control group as $0.51 \mathrm{~N} / \mathrm{mm}^{2}$ and the maximum bending strength was found in chainsaw control group as $12.84 \mathrm{~N} / \mathrm{mm}^{2}$. When the test results are evaluated, using chainsaw chips were found suitable for the production of general purpose particleboard in terms of physical and mechanical properties.
\end{abstract}

Keywords: Chainsaw dust, urea formaldehyde glue, particle board, physical and mechanical properties. 


\section{Giriş}

Dünyada ve ülkemizde mobilya üretiminde yaygın olarak kullanılan yonga levha, odun ve diğer lignoselülozik hammaddelerin elde edilen yongaların tutkallayıp basınç altında preslenmesiyle üretilen ahşap esaslı bir malzemedir (Youngquist,1999; İstek vd., 2017a). Nüfus artışına bağlı olarak orman ürünlerine olan talebin artmasıyla, sınırlı orman kaynaklarının daha etkin ve verimli kullanılması zorunlu hale gelmiştir. Bu bağlamda, odun ve diğer lignoselülozik maddeleri kullanarak üretim yapan endüstri kollarının hammadde sorunlarını çözebilmek ve ormanlar üzerindeki baskıyı azaltmak için alternatif kaynaklar araştırılmaktadır. Günümüze hızlı büyüyen ağaçlar türleri, orman endüstri atık ve artıkları, odun dışı malzemeler, yıllık bitki sapları, tarımsal artıklar levha sanayinde hammadde olarak daha etkin ve verimli kullanılabilmesi amacıyla çalışmalar yapılmaktadır (Nasser, 2012; Fiorelli vd., 2012). Ormancılık faaliyetleri sonucunda geri dönüştürülebilen ya da yeniden kullanılabilen önemli miktarda atık ortaya çıkmaktadır. Son on yıllarda bu atıkların kullanılabilir ürünlere dönüştürülmesine yönelik farklı araştırmalar mevcuttur (Clausen, 2000; Khedari vd., 2004; Dos Santos vd., 2014; Kurt, 2020).

Tarımsal ve diğer lignoselülozik atıklar çoğunlukla yakılarak bertaraf edilmekte ya da enerji üretiminde kullanılmaktadır. Bu kaynakların daha yüksek katma değerli bir ürüne dönüşebilme imkanı vardır. Kaldı ki bu hammaddeler yakıldığında karbon salınımı söz konusu olduğundan toprak ve hava kirliliği ile çevreye zarar verilmektedir (Nazerian vd., 2016). Yonga levha, düşük kalitedeki odun ve lignoselülozik hammaddelerden üretilebilmektedir. Üretim süreçlerinde odun, kabuk ve diğer orman endüstri artıklarının kullanılabilmesi, dolayısıyla düşük kalitedeki hammadde katma değerli bir ürüne dönüşmüş olur. Böylece çevresel ve ekonomik bir katkı da elde edilir (Maloney 1993; Cai vd., 2004). Ahşap esaslı levha üretimi için alternatif hammadde araştırmaları incelendiğinde; buğday samanı (İstek 1999; Eroğlu vd., 2000; Eroğlu vd., 2001) ve mısır sapı (Mo vd., 2003; Halvarsson vd., 2008;), çay bitkisi ve kızılçam odunu (Nemli ve Kalaycıŏglu,1997; Filiz vd.,2011), ayçiçeği sapları (Güler vd., 2006; Meinlschmidt vd., 2008;), kivi budama artıkları ve odun karışımı (Nemli vd., 2003), badem kabuğu (Guru vd., 2006;) Sera, domates ve patlıcan sap1 atıkları (Arslan, 2008; Güntekin ve Karakuş, 2008; Güntekin vd., 2009), pirinç kabuğu (Tansey,1995; Ciannamea vd., 2010), pamuk sapı ve karpeli (El-Mously vd., 1999;Guler ve Ozen, 2004; Alma vd., 2005; Mohamed vd., 2008), findık kabuğu (Cöpür vd.,2007), atık çim kırpıntıları (Nemli vd.,2009), orman gülü (Akgül ve Çamlıbel, 2008), palmiye, hurma yaprak ve dalları (El-Mously vd., 1993;Nemli vd., 2001;Lin vd., 2008;Hegazy vd., 2010;), şeker kamış1 küspesi (Xu vd., 2009), keten yongaları (Papadopoulos vd., 2003), kenaf (Grigoriou vd., 2000; Xu vd.,2003), üzüm asmas1 (Ntalos ve Grigoriou, 2002), bambu yonga ve atıkları (Papadopoulos vd., 2004; Laemlaksakul, 2010; Valarelli et. al 2014) üzerine araştırmalar yapılmıştır. Ahşap esaslı kompozitler üzerinde yapılan bu çalışmalar levha özelliklerinin çoğunlukla genel amaçlara yönelik kullanımlar için uygun olduğunu göstermiştir (Kalaycıŏglu vd., 2005; Güler vd., 2006; Pan vd., 2007; Bardak vd., 2010; Ortuno vd., 2011; Güler ve Büyüksari, 2011; Juliana, vd., 2012; Topbaşlı ve Sevinçli, 2017; Güler ve Beram, 2018; Güler ve Yaşar, 2018). Bununla birlikte bu alternatif hammaddelerden yıllık bitkilerin hacimsel olarak çok yer kaplaması ya da elde edilen levhaların düşük boyutsal stabilite ve yetersiz mekanik özelliklere sahip olması gibi bazı dezavantajlara da sahip olduğu belirtilmiştir (Iswanto, vd., 2014). Türkiye gelişen bir orman ürünleri sanayisine sahip olup, ahşap esaslı levha sektöründe de büyük yatırımları vardır. Özellikle yonga levha ve lif levha (MDF) üretim miktarları açısından Avrupa'da ve Dünya'da ilk sıralarda yer almaktadır (İstek vd., 2017b). Artan hammadde ihtiyacını karşılamak üzere ülkemizde de farklı lignoselülozik malzemelerin kullanımına yönelik araştırmalar devam etmektedir.

Bu çalışmada motorlu testere talaşının (MTT) yonga levha üretimine uygunluğu araştırılmıştır. Bu amaçla farklı ağaç türlerinden elde edilen MTT ile endüstriyel üretim yapan işletmelerden temin edilen odun yongaları (EY) ayrı ayrı ve farklı oranlarda karışım halinde kullanılarak yonga levha üretilmiştir. Elde edilen levhaların fiziksel ve mekanik özellikleri standart değerler ile karşılaştırmalı olarak değerlendirilmiş ve MTT'nin yonga levha üretimine uygunluğu irdelenmiştir.

\section{Materyal ve Metot}

\subsection{Materyal}

Bu çalışmada iğne yapraklı ağaçlardan (IYYA) Sahil çamı (Pinus pinaster), yapraklı ağaçlardan (YA) Doğu kayını (Fagus orientalis) ve Adi dişbudak (Fraxinus excelsior) odunlarının motorlu testere ile kesilmesi sonucu elde edilen testere talaşları ile endüstriyel odun yongaları hammadde olarak kullanılmıştır. Endüstriyel yongalar ticari bir yonga levha işletmesinden temin edilmiş olup, \%60 İYA, \%40 YA odun karışımlarından oluşmaktadır. Deney levhaları üretiminde motorlu testere talaşları (MTT) ve endüstriyel odun yongaları (EY) \%65 iğne yapraklı, \%35 yapraklı ağaç yonga karışım oranlarında kullanılmıştır. Motorlu testere talaş üretimi Bartın Üniversitesi Mobilya 
atölyesinde gerçekleştirilmiştir. Hazırlanan tüm talaş ve yongalar Orman Endüstri Mühendisliği Bölümü Kompozit Levha Laboratuvarında elenerek sınıflandırılmış ve \%1-2 rutubete kadar kurutularak polietilen çuvallarda rutubet almayacak şekilde depolanmıştır. Deney levhaları üretiminde bağlayıcı olarak üre formaldehit (UF) tutkalı ve sertleştirici olarak $\left(\mathrm{NH}_{4} \mathrm{Cl}\right)$ çözeltisi kullanılmıştır. UF tutkalı \%50 konsantrasyonda, Kastamonu Entegre Ağaç Sanayi ve Ticaret A.Ş. Kastamonu Yonga Levha (YONGAPAN) işletmesinden, amonyum klorür ticari bir işletmeden temin edilmiştir.

\subsection{Metot}

Yonga ve talaşların sınıflandırılmasında 3 katlı elek takımı kullanılmıştır. Elemede 9,6 mm açıklıktan geçip 2,36 mm elek üzerinde kalan yongalar orta tabakada, 2,36 mm açıklıktan geçip $1 \mathrm{~mm}$ üzerinde kalan yongalar ise yüzey tabakalarında kullanılmıştır. Elenmiş yongalar ayrı ayrı etüvde $120^{\circ} \mathrm{C}$ 'de \%1-2 rutubete kadar kurutulmuştur. Deneme levhaları tam kuru yonga ağırlığına oranla $\% 60$ orta, $\% 40$ yüzey tabaka yongalarından oluşacak şekilde dış tabakalarda \%10, orta tabakalarda \%8 UF reçinesi kullanılarak tutkallanmıştır. Sertleştirici olarak \%30 luk $\mathrm{NH}_{4} \mathrm{Cl}$ çözeltisinden tam kuru tutkala oranla \%1 oranında ilave edilmiştir. Deney levhaları 12 mm kalınlık ve $0,65 \mathrm{~g} / \mathrm{cm}^{3}$ yoğunlukta üretilmiştir. Tablo 1'de deney levhalarının orta ve yüzey tabakalarında kullanılan yonga tipi ve kullanım oranları görülmektedir.

Tablo 1. Deney levhalarının orta ve yüzey tabakalarında kullanılan yonga tipi ve kullanım oranları.

\begin{tabular}{cccccc}
\hline & \multicolumn{2}{c}{$\begin{array}{c}\text { Orta Tabaka Yongası } \\
(\boldsymbol{\%})\end{array}$} & \multicolumn{2}{c}{$\begin{array}{c}\text { Yüzey Tabaka Yongası } \\
(\boldsymbol{\%})\end{array}$} & Levha sayısı \\
\cline { 2 - 6 } Levha grubu & $\begin{array}{c}\text { MTT } \\
(\boldsymbol{\%})\end{array}$ & $\begin{array}{c}\text { EY } \\
(\boldsymbol{\%})\end{array}$ & $\begin{array}{c}\text { MTT } \\
(\boldsymbol{\%})\end{array}$ & $\begin{array}{c}\text { EY } \\
(\boldsymbol{\%})\end{array}$ & \\
\hline K1 (EY) Kontrol & 0 & 60 & 0 & 40 & 3 \\
K2 (MTT) Kontrol & 60 & 0 & 40 & 0 & 3 \\
A & 0 & 60 & 20 & 20 & 3 \\
B & 60 & 0 & 20 & 20 & 3 \\
C & 30 & 30 & 0 & 40 & 3 \\
D & 30 & 30 & 40 & 0 & 3 \\
E & 0 & 60 & 40 & 0 & 3 \\
F & 60 & 0 & 0 & 40 & \\
\hline
\end{tabular}

Tablo 1'de görüldüğü gibi ikisi EY ve MTT kontrol grubu olmak üzere toplam 8 farklı grupta 24 adet levha üretilmiştir. Deney levhaları $12 \mathrm{~mm}$ kalınlık, $400 \mathrm{X} 400 \mathrm{~mm}$ boyutlarda, $170-180{ }^{\circ} \mathrm{C}$ pres sıcaklığı, $160-170 \mathrm{bar}$ pres basınc1, 4 dakika pres süresi şartlarında üretilmiştir.

\subsection{Levha Özelliklerinin Belirlenmesi}

TS EN 326-1 standardına göre hazırlanan deney örnekleri $20 \pm 2^{\circ} \mathrm{C}$ ve $\% 65 \pm 5$ bağıl nem şartlarında kondisyonlanmış ve Tablo 2'de belirtilen deneyler ilgili standartlara göre yapılmıştır.

Tablo 2. Fiziksel ve mekanik özelliklerin belirlenmesinde kullanılan standartlar.

\begin{tabular}{ll}
\hline Özellik & Standartlar \\
\hline Rutubet & TS EN 322 (1999) \\
Yoğunluk & TS EN 323 (1999) \\
Kalınlığına şişme & TS EN 317 (1999) \\
Su alma & ASTM D1037 (2006) \\
Eğilme direnci ve Eğilmede elastikiyet modülü direnci & TS EN 310 (1999) \\
Yüzeye dik çekme direnci & TS EN 319 (1999) \\
Deney numunelerinin hazırlanması & TS EN 326-1(1999) \\
Yonga levhalar - Özellikler & TS EN 312 (2012) \\
\hline
\end{tabular}

Fiziksel ve mekanik özelliklerin yanında EY ve MTT yongalarının bağlanma özellikleri SEM analizi ile incelenmiştir. Elde edilen veriler SPSS programı kullanılarak istatistiksel olarak analiz edilerek, grup içi ve gruplar arası farklılıklar DUNCAN testi ile belirlenerek sonuçlar değerlendirilmiştir. 


\section{Bulgular ve Tartışma}

Deney levhalarının yoğunluk ve rutubet oranları ile 2 saat ve 24 saat ( 2 h, 24 h) kalınlığına şişme (TS) ve su alma (WA) özelliklerine ait ortalama veriler ve standart sapma ve istatistik değerlendirmeler Tablo 3 'te görülmektedir.

Tablo 3. Deney levhalarının fiziksel özelliklerine ilişkin ortalama değerler.

\begin{tabular}{|c|c|c|c|c|c|c|c|}
\hline \multirow{2}{*}{\multicolumn{2}{|c|}{ Levha grubu }} & \multirow{2}{*}{$\begin{array}{c}\text { Rutubet } \\
(\%)\end{array}$} & \multirow{2}{*}{$\begin{array}{r}\text { Yoğunluk } \\
\qquad\left(\mathrm{g} / \mathrm{cm}^{3}\right)\end{array}$} & \multicolumn{2}{|c|}{$\begin{array}{c}\text { Kalınlığına Şişme } \\
\text { (TS) }(\%)\end{array}$} & \multicolumn{2}{|c|}{$\begin{array}{l}\text { Su alma } \\
(\text { WA) }(\%)\end{array}$} \\
\hline & & & & $2 \mathrm{~h}$ & $24 \mathrm{~h}$ & $2 \mathrm{~h}$ & $24 \mathrm{~h}$ \\
\hline \multirow{2}{*}{$\begin{array}{l}\text { K1 (EY) } \\
\text { Kontrol } \\
\end{array}$} & $\mathbf{X}$ & 6,61 & 0,67 & $29,51 \mathrm{ab}$ & $32,38 \mathrm{abc}$ & $75,14 a$ & $81,87 \mathrm{a}$ \\
\hline & \pm sd & 0,15 & 0,05 & 4,01 & 4,92 & 4,40 & 5,78 \\
\hline \multirow{2}{*}{$\begin{array}{c}\text { K2 }(\text { MTT) } \\
\text { Kontrol } \\
\end{array}$} & $\mathbf{X}$ & 6,24 & 0,66 & $27,34 a$ & $29,05 \mathrm{a}$ & $83,85 \mathrm{bcd}$ & $94,86 \mathrm{bcd}$ \\
\hline & \pm sd & 0,14 & 0,05 & 3,13 & 9,87 & 5,85 & 6,58 \\
\hline \multirow{2}{*}{$\mathbf{A}$} & $\mathbf{X}$ & 6,20 & 0,67 & $30,86 a b c$ & $34,68 \mathrm{bc}$ & $78,30 \mathrm{ab}$ & $88,93 \mathrm{~b}$ \\
\hline & \pm sd & 0,08 & 0,05 & 3,58 & 3,60 & 4,14 & 4,78 \\
\hline \multirow{2}{*}{ B } & $\mathbf{X}$ & 6,21 & 0,65 & $31,07 \mathrm{abc}$ & $35,65 \mathrm{bc}$ & $89,68 \mathrm{e}$ & $99,71 \mathrm{~d}$ \\
\hline & \pm sd & 0,09 & 0,05 & 6,77 & 7,73 & 6,96 & 6,59 \\
\hline \multirow{2}{*}{$\mathbf{C}$} & $\mathbf{X}$ & 6,30 & 0,66 & $29,17 \mathrm{ab}$ & $31,98 \mathrm{ab}$ & $82,84 b c$ & $92,77 b c$ \\
\hline & $\pm \mathbf{s d}$ & 0,12 & 0,05 & 3,11 & 3,63 & 6,58 & 6,38 \\
\hline \multirow{2}{*}{ D } & $\mathbf{X}$ & 6,76 & 0,64 & $32,44 \mathrm{bc}$ & $36,73 \mathrm{bc}$ & $89,16 \mathrm{de}$ & $98,11 \mathrm{~cd}$ \\
\hline & \pm sd & 0,18 & 0,06 & 4,00 & 4,54 & 8,17 & 7,47 \\
\hline \multirow{2}{*}{$\mathbf{E}$} & $\mathbf{X}$ & 6,80 & 0,66 & $34,44 \mathrm{c}$ & $38,02 \mathrm{c}$ & 84,12 bcde & $92,44 b c$ \\
\hline & \pm sd & 0,28 & 0,04 & 2,98 & 3,30 & 3,91 & 3,33 \\
\hline \multirow{2}{*}{$\mathbf{F}$} & $\mathbf{X}$ & 6,71 & 0,65 & $30,21 \mathrm{ab}$ & $33,21 a b c$ & 87,31 cde & $97,75 \mathrm{~cd}$ \\
\hline & \pm sd & 0,13 & 0,06 & 2,95 & 3,56 & 7,71 & 7,84 \\
\hline
\end{tabular}

X: ortalama, sd: standart sapma, aynı sütunda bulunan aynı haflar (a,b,c ) istatistiksel olarak önemli farklılık olmadığını göstermektedir

Tablo 3 incelendiğinde ortalama özgül ağırlık değerleri 0,64-0,67 g/cm3 arasında değişmekte olup, bu değerler çalışmada üretilmesi hedeflenen $0,65 \mathrm{~g} / \mathrm{cm}^{3}$ yoğunluk değerleri bakımından TS EN 312 (2012) standardına uygun olduğu anlaşılmaktadır. İstek ve Sıradağ (2013) yapmış oldukları çalışmada yonga levhalarda yoğunluk değişiminin \%10'dan fazla olmasının levha özelliklerini istatistiksel olarak anlamlı etkilediğini belirtmişlerdir. Çalışmada elde ettiğimiz değerler ele alındığında, hedeflenen özgül ağırlık değerinden sapmanın en fazla \%13 olduğu hesaplanmıştır. Üretilen deney levhalarının denge rutubetlerinin \%6-7 arasında olduğu belirlenmiştir. Deney levhaları rutubet değişiminin TS EN 312'e (2012) standardında istenen \%5-13 rutubet aralığında olduğu görülmektedir. Şekil 1'de levha gruplarının su alma (WA) ve kalınlığına şişme (TS) değerleri karşılaştırmalı olarak görülmektedir.

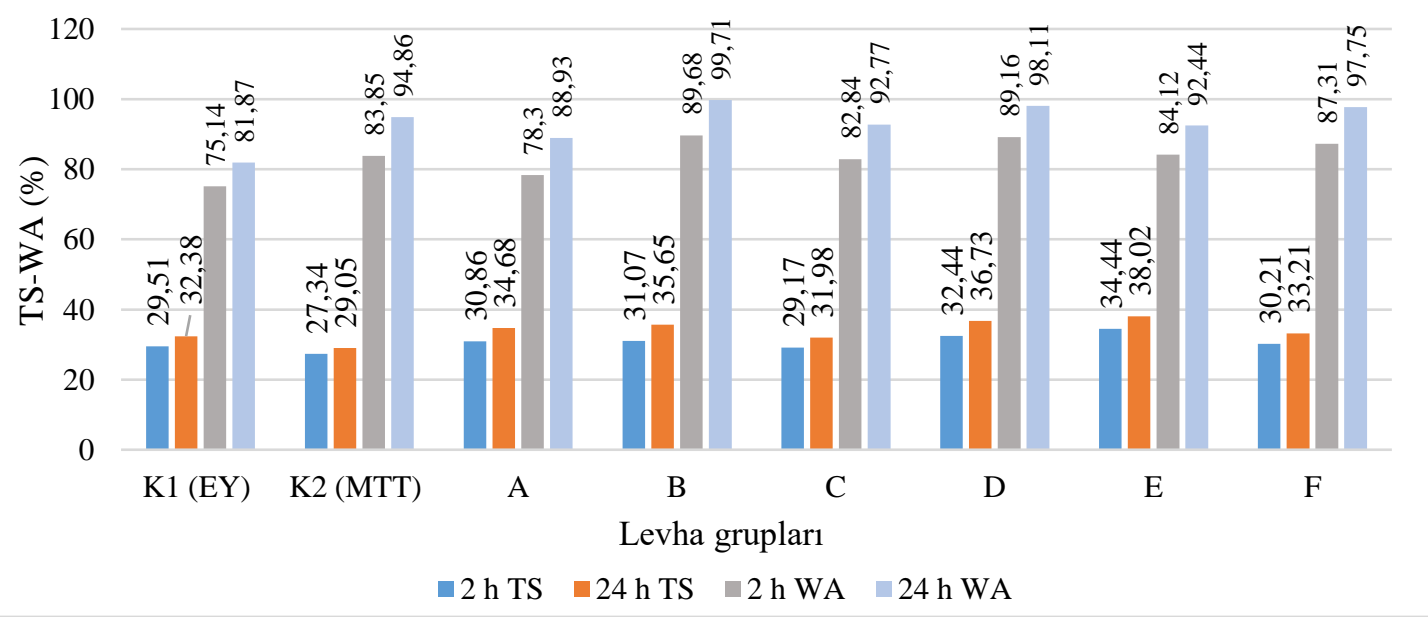

Şekil 1. Levha gruplarının su alma ve kalınlığına şişme değerleri. 
2 ve 24 saatlik ortalama kalınlığına şişme ve su alma verilerinin istatistiksel değerlendirmesinde gruplar arası önemli farklılıkların olduğu belirlenmiștir. Kontrol grupları K1 (\%100 EY) ile K2 (\% 100 MTT) örneklerinin kalınlığına şişme oranları karşılaştırıldığında istatistik olarak önemli bir farkın olmadığı ancak su alma oranlarının K1 kontrol grubunda daha iyi olduğu ve K2 grup levhalarla anlamlı farklılıkların olduğu belirlenmiştir. EY ve MTT karışım olarak üretilen levha örneklerinde 2 saat kalınlığına şişme verileri istatistiksel olarak değerlendirildiğinde $\mathrm{C}$ grubu ile $\mathrm{E}$ grubu örnekler arasında anlamlı fark olduğu hesaplanmıștır. Diğer gruplar arasında ise istatistiksel olarak farklılık olmadığ1 görülmüştür. \%30 MTT, \%30 EY ile kontrol K1 levhalarına göre kalınlığına şişme oranı azalmıştır. 2 ve 24 saat kalınlığına şişme oranı orta tabakada \%60 EY, yüzey tabakasında $\% 40$ oranında tek başına MTT kullanılan E grubunda en yüksek değerde olup tek başına MTT kullanımının levhaların şişmesini olumsuz olarak etkilediği tespit edilmiştir. EY ile MTT kontrol grubu levhalar WA oranlarının istatistiksel olarak farklılık gösterdiği ve diğer bazı gruplar arasında $\% 95$ düzeyinde istatistiksel olarak anlamlı farklılıklar olduğu belirlenmiştir. Özellikle A grubu ile B grubu test örneklerinin 2 ve 24 saat WA değerlerinin arasında anlamlı fark olduğu bulunmuştur. WA oranlarının 2 ve 24 saat için en düşük sırasıyla $\% 75,14$ ve \%81,87 ile EY kontrol grubunda elde edilmiștir. EY ve MTT'nin karıșım halinde kullanılması ile elde edilen tüm değerlerin bu gruptan daha yüksek olduğu anlaşılmıştır. Karakuş (2007), sera atıkları (domates, patlıcan ve biber) kullanılarak ürettiği üç tabakalı orta yoğunluklu yonga levhaların kalınlığa şişme değerlerini $\% 44$ ile \%117 arasında, Filiz vd., (2011) ise çay bitkisi atıklarından ürettiği düşük yoğunluğa sahip yonga levhaların \%17 ile \%34.8 arasında olduğunu tespit etmiștir. Bir başka çalışmada ise lavanta bitkisi ile kızılçam yongalarından elde edilen orta yoğunlukta levha gruplarının kalınlığa şişme değerlerinin \%34,36 ile \%76,98 arasında olduğu belirtilmiştir (Sevinçli, 2014). Bu sonuçların çalışmamızda MTT kullanılarak üretilen levha gruplarında elde edilen kalınlığa şişme değerleri ile benzerlik gösterdiği tespit edilmiştir. Deney levhalarının mekanik özelliklerine ilişkin ortalama değerler ile standart sapma değerleri Tablo 4 'te görülmektedir.

Tablo 4. Deney levhalarının mekanik özelliklerine ilişkin ortalama değerler.

\begin{tabular}{|c|c|c|c|c|}
\hline \multicolumn{2}{|c|}{ Levha grubu } & \multirow{2}{*}{$\frac{\mathbf{B S}\left(\mathbf{N} / \mathbf{m m}^{\mathbf{2}}\right)}{12,23 \mathrm{a}}$} & \multirow{2}{*}{$\frac{\operatorname{MOE}\left(\mathbf{N} / \mathbf{m m}^{\mathbf{2}}\right)}{1583,93 \mathrm{~b}}$} & \multirow{2}{*}{$\frac{\mathbf{I B}\left(\mathbf{N} / \mathbf{m m}^{2}\right)}{0,51 \mathrm{~b}}$} \\
\hline K1 (EY) & $\mathbf{X}$ & & & \\
\hline Kontrol & \pm sd & 2,79 & 467,87 & 0,02 \\
\hline \multirow{2}{*}{$\begin{array}{c}\text { K2 (MTT) } \\
\text { Kontrol } \\
\end{array}$} & $\mathbf{X}$ & $12,84 \mathrm{a}$ & $1477,57 \mathrm{ab}$ & $0,48 \mathrm{ab}$ \\
\hline & \pm sd & 2,24 & 249,80 & 0,07 \\
\hline \multirow{2}{*}{$\mathbf{A}$} & $\mathbf{X}$ & $12,05 \mathrm{a}$ & $1405,14 \mathrm{ab}$ & $0,28 \mathrm{a}$ \\
\hline & \pm sd & 2,45 & 371,59 & 0,01 \\
\hline \multirow{2}{*}{ B } & $\mathbf{X}$ & $11,16 \mathrm{a}$ & $1160,15 \mathrm{ab}$ & $0,37 \mathrm{ab}$ \\
\hline & \pm sd & 1,20 & 298,37 & 0,07 \\
\hline \multirow{2}{*}{ C } & $\mathbf{X}$ & $10,83 \mathrm{a}$ & $1251,08 \mathrm{ab}$ & $0,46 \mathrm{ab}$ \\
\hline & \pm sd & 2,56 & 313,37 & 0,05 \\
\hline \multirow{2}{*}{ D } & $\mathbf{X}$ & $11,92 \mathrm{a}$ & $1251,05 \mathrm{ab}$ & $0,40 \mathrm{ab}$ \\
\hline & \pm sd & 1,79 & 261,09 & 0,04 \\
\hline \multirow{2}{*}{$\mathbf{E}$} & $\mathbf{X}$ & $10,29 a$ & $1225,14 \mathrm{ab}$ & $0,42 \mathrm{ab}$ \\
\hline & \pm sd & 2,97 & 354,17 & 0,02 \\
\hline \multirow{2}{*}{$\mathbf{F}$} & $\mathbf{X}$ & $10,31 \mathrm{a}$ & $1128,48 \mathrm{a}$ & $0,49 \mathrm{ab}$ \\
\hline & \pm sd & 2,52 & 303,36 & 0,02 \\
\hline \multicolumn{2}{|c|}{ Levha sınıfi } & \multicolumn{3}{|c|}{ TS EN 312 (2012) gereklilik } \\
\hline \multicolumn{2}{|c|}{ P1 } & 10 & $*$ & 0,24 \\
\hline \multicolumn{2}{|l|}{ P2 } & 11 & 1600 & 0,35 \\
\hline \multicolumn{2}{|l|}{ P3 } & 14 & 1950 & 0,45 \\
\hline
\end{tabular}

X: ortalama veriler, sd: standart sapma, aynı sütunda bulunan aynı haflar (a,b,c ) istatistiksel olarak önemli farklılıkları göstermektedir.

Tablo 4 incelendiğinde yüzeye IB direnci tamamen EY ile üretilen K1 grubunda en yüksek 0,51 N/mm² olarak ölçülürken, en düşük $0,28 \mathrm{~N} / \mathrm{mm}^{2}$ ile sadece yüzey tabakasında $\% 20$ oranında MTT kullanılan A grubunda görülmüştür. Orta tabakalarda sadece EY kullanılan gruplarda E grubunda yüzeye IB direnci $0,42 \mathrm{~N} / \mathrm{mm}^{2}$, A grubunda $0,28 \mathrm{~N} / \mathrm{mm}^{2}$ olarak ölçülmüştür. Benzer bir şekilde orta tabakalarında sadece MTT kullanılan B grubunda $0,37 \mathrm{~N} / \mathrm{mm}^{2}$ olan IB direnci, yüzey tabakasında sadece EY kullanılan F grubunda $0,49 \mathrm{~N} / \mathrm{mm}^{2}$ olarak ölçülmüsşür. Bu sonuçlara göre yonga levha üretiminde yüzey tabakalarında tek tip yonga kullanımının MTT ve EY karışımı kullanımına göre daha yüksek IB direnci verdiğini göstermektedir. Orta tabakalarda eşit miktarda veya aynı tip yonga kullanılan $\mathrm{C}$ ve $\mathrm{D}$ grupları karşılaştırıldığında, yüzey tabakasında sadece EY kullanılan C grubunda IB direnci $0,46 \mathrm{~N} / \mathrm{mm}^{2}$, yüzey tabakasında sadece MTT kullanılan D grubunda ise $0,40 \mathrm{~N} / \mathrm{mm}^{2}$ olarak elde edilmiş̧ir. Benzer bir durum F ve K1 gruplarında da görülmektedir. Bu sonuçlara göre orta tabaka yonga tipi ve oranı aynı olmak koşulu ile yüzey tabakalarında EY kullanımı ile MTT kullanımına göre daha yüksek IB 
direnci elde edildiğini göstermektedir. Levha gruplarının eğilme direnci ve yüzeye dik çekme direnci değerleri Şekil 2'de karşılaştırmalı olarak verilmişstir.

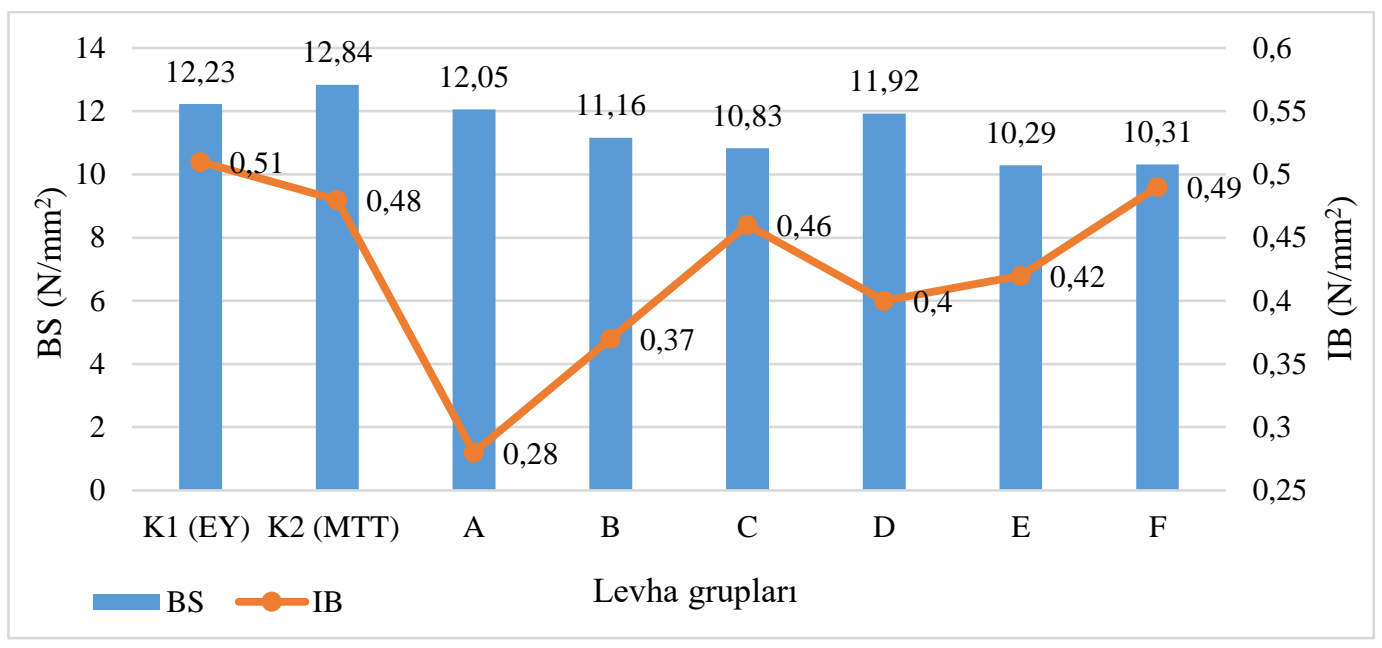

Şekil 2. Levha gruplarının eğilme direnci ve yüzeye dik çekme direnci değerleri.

Elde edilen sonuçlar TS EN 312 (2012) standartları ile karşılaştırıldığında IB direnci bakımından tüm levha gruplarında kuru şartlarda kullanılan genel amaçlı levhalar için özellikler (Tip P1) standardında belirtilen 0,28 $\mathrm{N} / \mathrm{mm}^{2}$ değerinin karşılandığı görülmektedir. Ayrıca, K1, K2, C, D, E ve F grupları Tip P2 (Kuru şartlarda iç uygulamalarda (mobilya dâhil) kullanılan levhalar için özellikler) ve Tip P4 (Kuru şartlarda kullanılan yük taşıyıcı levhalar için özellikler) için gerekli değer olan $0,40 \mathrm{~N} / \mathrm{mm}^{2}$ değerini karşılamaktadır. Bunla birlikte K1, K2, C ve F levha grupları Tip P3 (Nemli şartlarda kullanılan yük taşıyıcı olmayan levhalar) için belirtilen 0,45 $\mathrm{N} / \mathrm{mm}^{2}$ değerini de karşılamaktadır. Levha gruplarının eğilmede elastikiyet modülü direnci değerleri Şekil 3'te verilmiştir.

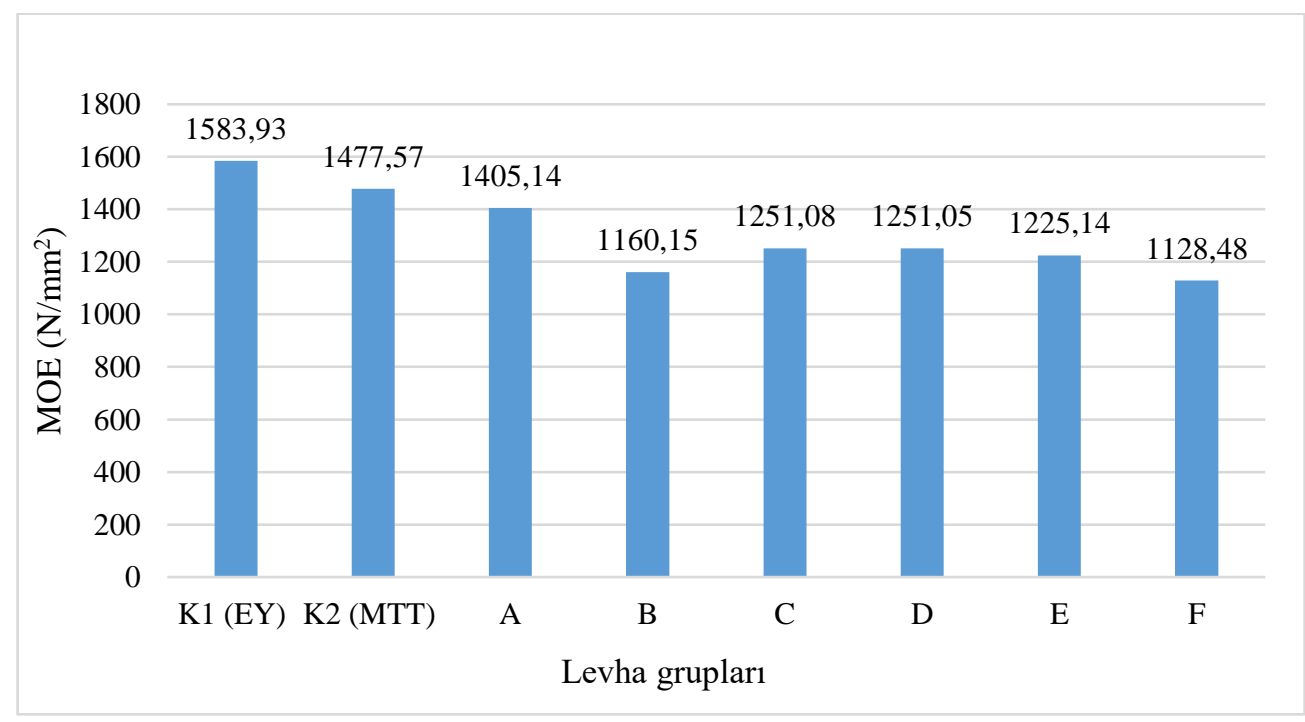

Şekil 3. Levha gruplarının eğilmede elastikiyet modülü direnci değerleri.

Levha gruplarının ortalama BS ve MOE değerleri incelendiğinde MTT ile üretilen K2 grubunda en yüksek BS $12,84 \mathrm{~N} / \mathrm{mm}^{2}$ elde edilmiştir. En düşük BS değeri 10,29 N/mm $\mathrm{mm}^{2}$ ile orta tabakada $\% 60$ EY ile üst tabakada $\% 40$ MTT kullanılan E grubunda elde edilmiştir. Ancak elde edilen tüm veriler arasında \%95 güvenle istatistiksel olarak bir farkın olmadığı belirlenmiştir. Buna karşın, MOE değerleri incelendiğinde K1 grubu ile F grubu arasında önemli fark olduğu belirlenmiştir $(\mathrm{p}<0,05)$. K2, B ve F grupları karşılaştırıldığında BS ve MOE değerleri sirasiyla K2 grubunda 12,84 ve $1477,57 \mathrm{~N} / \mathrm{mm}^{2}$, B grubunda 11,16 ve $1160,15 \mathrm{~N} / \mathrm{mm}^{2}$, F grubunda 10,31 ve $1128,48 \mathrm{~N} / \mathrm{mm}^{2}$ olarak bulunmuştur. Bu gruplar arasında BS için istatistiksel olarak fark bulunmazken, MOE için F grubu ile B ve K2 grupları arasında önemli bir fark olduğu tespit edilmiştir. A, E ve K1 grupları karşılaştırıldığında BS ve MOE değerleri sırasıyla K1 grubunda 12,23 ve 1583,93 N/mm², A grubunda 12,05 ve 
$1405,14 \mathrm{~N} / \mathrm{mm}^{2}$ ve E grubunda ise 10,29 ve $1225,14 \mathrm{~N} / \mathrm{mm}^{2}$ olarak bulunmuş olup, bu gruplar arasında istatistiksel olarak fark olmadığ 1 anlaşılmıştır.

TS EN 312 (2012) standardına göre BS değeri için K2 levha grubunda elde edilen 12,84 N/mm² değerinin, Tip P1 levha sınıfı gerekliliğini karşılamaktadır. MOE değerleri ise TS EN 312 (2012) standardında belirtilen değerlerin altında olduğu anlaşılmıştır. Şekil 4'te levha gruplarına ait SEM görüntüleri verilmiştir. MTT yongalarının daha ince yapıda olduğu ve MTT kullanım oranı arttıkça daha geniş yüzeyler elde edildiği anlaşılmıştır. Farklı çalışmalarda yonga yapısının fiziksel ve mekanik özellikler üzerinde etkili olduğu belirtilmiştir (Baskaran vd., 2017; Hashim vd., 2010; Marashdeh vd., 2011).
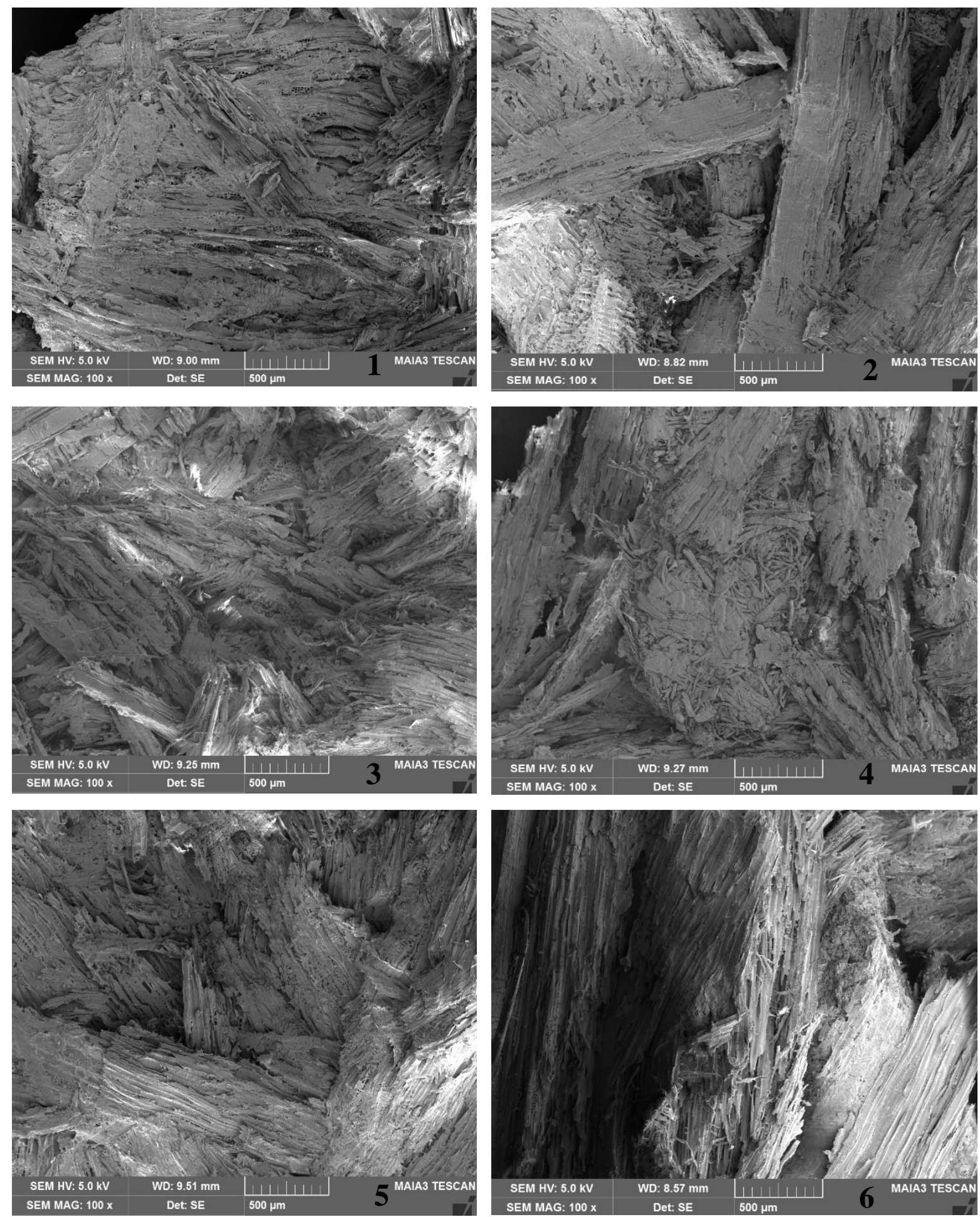

Şekil 4. Levha gruplarına ait SEM görüntüleri (1: K1 (EY), 2: K2 (MTT), 3:A, 4:B, 5:C, 6:D). 


\section{Sonuç ve Öneriler}

$\mathrm{Bu}$ çalışmada yonga levha üretiminde iğne yapraklı ağaçlardan Sahil çamı (Pinus pinaster), yapraklı ağaçlardan da Doğu kayını (Fagus orientalis) ve Adi dişbudak (Fraxinus excelsior) odunlarından motorlu testere ile üretilen yongalar ve endüstriyel odun yongası kullanılmıştır. Üretilen levhaların fiziksel ve mekanik özellikleri incelediğinde yoğunluk ve rutubet değerlerinin standartlarda istenen koşulları sağladığı, 2 ve 24 saatlik ortalama WA ve TS özellikleri ise standart özellikleri karşılamadığı belirlenmiştir. Bu durumun su itici katkı maddeleri kullanımı iyileştirilebilir olduğu bilinmektedir. Mekanik özellikler irdelendiğinde tüm levha grupları için IB değerleri P1 levha sınıfı özelliklerini karşıladığı sonucuna varılmıştır. BS değerleri için sadece K2 grubu Tip P1 levha sınıfi özelliklerini karşılarken, MOE değerleri ise standartta aranan özelikleri sağlamadığı görülmüştür. Bu durumun laboratuvar üretim koşulları ile tutkal ve hammadde kaynaklı olabileceği düşünülmektedir. MTT ve NY karışımlarında mekanik özelliklerin nispeten daha düşük olması MTT kullanımı ile yonga yüzey alanının genişlemesi ve birim hacimdeki tutkal miktarının yeterli olmaması ve MTT yongalarının EY'lere göre daha ince olmasına bağlı olduğu, dolayısı ile bireysel yonga direncini düşürdüğü kanaatine varılmıştır. Elde edilen sonuçlara göre aşağıdaki öneriler yapılabilir;

- Genel amaçlı mobilya üretiminde fazla direnç gerektirmeyen kullanımlar için MTT yongalarının levha üretiminde kullanılabileceği görülmüştür.

- Genel olarak MTT ve EY'nin tek başına kullanılmaları durumunda karışım halinde kullanılmalarına göre daha iyi fiziksel ve mekanik özellikler gösterdiği belirlenmiştir. Kullanım yerinde beklenen performansa göre üretimde bu husus göz önünde bulundurulabilir.

- Levhaların fiziksel özelliklerinden su alma ve kalınlığına şişme değerlerinin yüksek olması nedeniyle kullanım yerine de bağlı olarak mutlaka hidrofob maddeler kullanılmalıdır.

- Farklı ağaç türlerinin MTT yongaları ile tek başlarına ya da EY ile karışım halinde kullanılarak farklı çalışmalar yapılabilir.

- $\quad$ MTT ve EY karışımı ile üretilen levhalarda daha iyi fiziksel ve mekanik özellikler sağlamak amacıyla farklı özellikteki tutkallar kullanılması önerilir.

\section{Kaynaklar}

1. Akgul, M., Camlibel, O. (2008). Manufacture of medium density fiberboard (MDF) panels from rhododendron (R. ponticum L.) biomass. Building and Environment, 43(4), 438-443.

2. Alma, M. H., Kalaycioglu, H., Bektas, A., Tutus, A. (2005). Properties of cotton carpel-based particleboards. Industrial Crops and Products, 22(2), 141-149.

3. Arslan, M. B. (2008). Surface Chemical Properties of Forest and Agriculture Residue Based Composites Investigated, Msc. Theses, Suleyman Demirel University, Graduate School of Applied and Naturel Sciences, (Turkish, Abstract in English), 91p.

4. ASTM D1037 (2006). American Society for Testing and Materials. Annual book of ASTM standards. 100 Barr Harbor Dr., West Conshohocken, PA 19428, 1999.

5. Bardak, S., Nemli, G., Sari, B., Baharoglu, M., Zekovic, E. (2010). Manufacture and properties of particleboard composite from waste sanding dusts. High Temperature Materials and Processes, 29(3), 159-168.

6. Baskaran, M., Azmi, N. A. C. H., Hashim, R., Sulaiman, O. (2017). Properties of binderless particleboard and particleboard with addition of urea formaldehyde made from oil palm trunk waste. Journal of Physical Science, 28(3), 151-159.

7. Cai, Z., Wu, Q., Lee, J. N., Hiziroglu, S. (2004). Influence of board density, mat construction, and chip type on performance of particleboard made from eastern redcedar. Forest Products Journal, 54(12), 226232.

8. Ciannamea, E. M., Stefani, P. M, Ruseckaite, R. A. (2010). Medium-density particleboards from modified rice husks and soybean protein concentrate-based adhesives. Bioresource Technology, 101(2), 818-825.

9. Clausen, C. A. (2000). CCA removal from treated wood using a dual remediation process. Waste Management \& Research, 18(5), 485-488.

10. Çöpur, Y., Güler, C., Akgül, M., Taşçığlu, C. (2007). Some chemical properties of hazelnut husk and its suitability for particleboard production. Building and Environment, 42(7), 2568-2572.

11. Dos Santos, M. F. N., Rosane Ap G, B., Bezerra, B. S., Varum, H. S. (2014). Comparative study of the life cycle assessment of particleboards made of residues from sugarcane bagasse (Saccharum spp.) and pine wood shavings (Pinus elliottii). Journal of Cleaner Production, 64, 345-355. 
12. El-Mously, H. I., Megahed, M. M., Rakha, M. M. (1999). Investigation of the possibility of use of cotton stalks in particleboard manufacture. Sci. Bull. Fac. Eng. Ain Shams Univ. ISSN, 1110-1385.

13. El-Mously, H., El-Morshedy, M. M., Megahed, M. M., El-Hai, Y. A. (1993). Evaluation of particleboard made of palm leaves midribs as compared with flax board. In Proceedings of the 4th International Conference on Production Engineering and Design for Development, Cairo, Egypt (pp. 2729).

14. Eroğlu, H., İstek, A., Roy, T. K., Kibblewhite, R. P. (2000). Medium density fibreboard (MDF) manufacturing from wheat straw (Triticum aestivum L.). Inpaper Int, 4, 11-14.

15. Eroğlu, H., İstek, A., Usta, M. (2001). Buğday saplarından (Triticum aestivum L.) ve saman-odun karışımı liflerden orta yoğunlukta lif levha (MDF) üretimi. Pamukkale Üniversitesi Mühendislik Bilimleri Dergisi, 7(2), 305-311.

16. Filiz, M., Usta, P., Şahin, H.T. (2011). Evaluation of some technical properties obtained from the participleboard with melamine urea formaldehyde glue, red pine and tea waste. Süleyman Demirel University, Journal of Natural and Applied Sciences, 15(2), 88-93.

17. Fiorelli, J., Curtolo, D. D., Barrero, N. G., Savastano Jr., H., Pallone, E. M. A., Johnson, R. (2012). Particulate composite based on coconut fiber and castor oil polyurethane adhesive: An eco-efficient product, Industrial Crops and Products V. 40, p 69-75.

18. Grigoriou, A., Passialis, C., Voulgaridis, E. (2000). Experimental particleboards from kenaf plantations grown in Greece. Holz als Roh-und Werkstoff, 58(5), 309-314.

19. Güler, C., Büyüksarı, Ü. (2011). Effect of production parameters on the physical and mechanical properties of particleboards made from peanut (Arachis hypogaea L.) hull. BioResources, 6(4), 50275036.

20. Güler, C., Özen, R. (2004). Some properties of particleboards made from cotton stalks (Gossypium hirsitum L.)," Holz als Roh-und Werkstoff 62(1), 40-43.

21. Güler, C., Bektas, I., Kalaycioglu, H. (2006). The experimental particleboard manufacture from sunflower stalks (Helianthus annuus L.) and calabrian pine (Pinus brutia ten.). Forest Products Journal, 56(4), 56-60.

22. Güler, C., İbiş, M. (2018). Yongalevha üretiminde hammadde kaynaklarının optimizasyonu ve teknolojik yönden incelenmesi. Düzce Üniversitesi Bilim ve Teknoloji Dergisi, 6(4), 808-817.

23. Güler, G., Beram, A. (2018). Investigation of physical, mechanical and surface roughness properties of particleboards produced from chicory (Cichorium intybus L.) stalks. Journal of Bartin Faculty of Forestry, 20(2), 216-222.

24. Güler, G., Yaşar, S. (2018). Investigation of some chemical properties of kermes oak (Quercus coccifera L.) wood and its use in the particleboard production. Journal of Bartin Faculty of Forestry 20(2), 184193.

25. Güntekin, E., Karakus, B. (2008). Feasibility of using eggplant (Solanum melongena) stalks in the production of experimental particleboard. Industrial Crops and Products, 27(3), 354-358.

26. Güntekin, E., Üner, B., Karakus, B. (2009). Chemical composition of tomato (Solanum lycopersicum) stalk and suitability in the particleboard production. Journal of environmental biology, 30(5), 731-734.

27. Guru, M., Tekeli, M., I, Bilici. (2006). Manufacturing of urea-formaldehyde-based composite particleboard from almond shell. Materials and Design 27(10), 1148-1151.

28. Halvarsson, S., Edlund, H., Norgren, M. (2008). Properties of medium-density fibreboard (MDF) based on wheat straw and melamine modified urea formaldehyde (UMF) resin. Industrial crops and products, 28(1), 37-46.

29. Hashim, R., Saari, N., Sulaiman, O., Sugimoto, T., Hiziroglu, S., Sato, M., Tanaka, R. (2010). Effect of particle geometry on the properties of binderless particleboard manufactured from oil palm trunk. Materials \& Design, 31(9), 4251-4257.

30. Hegazy, S.S. Aref, I.M. (2010). Suitability of some fast-growing trees and date palm fronds for particleboard production. Forest Products Journal, 60(7), 599-604.

31. İstek, A. (1999). Buğday Saplarından (Triticum aestivum L.) Orta Yoğunlukta Lif Levha (MDF) Üretimi. Doktora Tezi, Zonguldak Karaelmas Üniversitesi, Fen Bilimleri Enstitüsü, Orman Endüstri Mühendisliği Anabilim Dalı, Bartın, $163 \mathrm{~s}$.

32. İstek A., Siradag, H., (2013). The Effect of Density on Particleboard Properties, International Caucasian Forestry Symposium, 932-938, 24-26 October 2013, Artvin, Turkey.

33. İstek, A., Gözalan, M., Ozlusoylu, İ. (2017a). The effects of surface coating and painting process on particleboard properties. Journal of Kastamonu Faculty of Forestry 17(4), 619-629.

34. İstek, A., Ozlusoylu, İ., Kizilkaya, A. (2017b). Turkish wood based panels'sector analysis. Journal of Bartin Faculty of Forestry 19(1), 132-138.

35. Iswanto, A. H., Azhar, I., Susilowati, A. (2014). Effect of resin type, pressing temperature and time on particleboard properties made from sorghum bagasse. Agriculture, Forestry and Fisheries, 3(2): 62-66. 
36. Juliana, A. H., Paridah, M. T., Rahim, S., Azowa, I. N., Anwar, U. M. K. (2012). Properties of particleboard made from kenaf (Hibiscus cannabinus L.) as function of particle geometry. Materials \& Design, 34, 406-411.

37. Kalaycioglu, H., Deniz, I., Hiziroglu, S. (2005). Some of the properties of particleboard made from paulownia. Journal of Wood Science, 51(4), 410-414.

38. Khedari, J., Nankongnab, N., Hirunlabh, J., Teekasap, S. (2004). New low-cost insulation particleboards from mixture of durian peel and coconut coir. Building and environment, 39(1), 59-65.

39. Kurt, R. (2020). Determining the priorities in utilization of forest residues as biomass: an A'wot analysis. Biofuels, Bioproducts and Biorefining, 14(2), 315-325.

40. Laemlaksakul, V. (2010). Physical and mechanical properties of particleboard from bamboo waste. World academy of science, engineering and technology, 40, 507-511.

41. Lin, C. J., Hiziroglu, S., Kan, S. M., Lai, H. W. (2008). Manufacturing particleboard panels from betel palm (Areca catechu Linn.). Journal of materials processing technology, 197(1-3), 445-448.

42. Maloney, T. (1993). Modem Particleboard and Dry-Process Fiberboard Manufacturing. Forest Products Society, Madison: WI.

43. Marashdeh, M. W., Hashim, R., Bauk, S., \& Sulaiman, O. (2011). Effect of particle size on the characterization of binderless particleboard made from Rhizophora spp. Mangrove wood for use as phantom material. BioResources, 6(4), 4028-4044.

44. Meinlschmidt, P., Schirp, A., Dix, B., Thole, V., Brinker, N. (2008). Agricultural Residues with Light Parenchyma Cells and Expandable Filler Materials for The Production of Lightweight Particleboards, In Proceedings of the International Panel Products Symposium, 179-188, 24th-26th September, Finland.

45. Mo, X., Cheng, E., Wang, D., Sun, X. S. (2003). Physical properties of medium density wheat straw particleboard using different adhesives. Industrial Crops and Products, 18(1), 47-53.

46. Mohamed, T.E. R.A. Nasser, (2008). "Effect of mixing three lignocellulosic materials on some properties of particleboard bonded with urea formaldehyde adhesive," J. Agric. Res. Kafer El-Sheikh Univ. 34(4), 1144-1163.

47. Nasser, R. A. (2012). Physical and mechanical properties of three-layer particleboard manufactured from the tree pruning of seven wood species," World Appl. Sci. J. 19(5), 741-753.

48. Nazerian, M., Beyki, Z., Gargarii, R. M., Kool, F. (2016). The effect of some technological production variables on mechanical and physical properties of particleboard manufactured from cotton (Gossypium hirsutum) stalks. Maderas. Ciencia y tecnología, 18(1), 167-178.

49. Nemli, G., Kalaycioğlu, H. (1997). An Alternative Material in Particleboard Industry: Residues of Tea Factory, Proceedings of The XI World Forestry Congress, 49, Vol: 4, Antalya, Turkey.

50. Nemli, G., Kırcı, H., Serdar, B., Ay, N. (2003). Suitability of kiwi prunings for particleboard manufacturing. Industrial Crops and Products, 17(1), 39-46.

51. Nemli, G., Demirel, S., Gumuskaya, E., Aslan, M., Acar, C. (2009). Feasibility of incorporating waste grass clipping (Lolium pernne L.) in particleboard composites. Waste Management, 29(13), 1129-1131.

52. Nemli, G., Kalaycioglu, H., Alp, T. (2001). Suitability of date palm (Phoenix dactyliferia) branches for particleboard production. Holz Roh-Werkstoff, 59(6), 411-412.

53. Ntalos, G. A., Grigoriou, A. H. (2002). Characterization and utilisation of vine prunings as a substitute for particleboard production. Industrial Crops and Products, 16(1), 59-68.

54. Ortuno, T. G., Rodríguez, J. A., García, M. T. F., García, M. F. V., García, C. E. F. (2011). "Evaluation of the physical and mechanical properties of particleboard made from giant reed (Arundo donax L.)," BioResources, 6(1), 477-486.

55. Pan, Z., Zheng, Y., Zhang, R., Jenkins, B. M. (2007). Physical properties of thin particleboard made from saline eucalyptus. Industrial Crops and Products, 26(2), 185-194.

56. Papadopoulos, A. N., Hill, C. A. S., Gkaraveli, A., Ntalos, G. A., Karastergiou, S. P. (2004). Bamboo chips (Bambusa vulgaris) as an alternative lignocellulosic raw material for particleboard manufacture. Holz als Roh - und Werkstoff, 62(1), 36-39.

57. Papadopoulos, A.N., R.B. Jamie and R.B. Hague, (2003). The potential for using flax (Linum usitatissimum L.) Shiv as a lignocellulosic raw material for particleboard. Industrial Crops and Products, 17(2), 143-147.

58. Tansey, P. (1995). Particleboard from rice straw. Xilon International, 8(83), 43-48.

59. Topbaşlı, B., Sevinçli, Y. (2017). Lavanta sap1 ve muz kabuğu kullanılarak üretilen yonga levhaların karşılaştırılması. Ejovoc (Electronic Journal of Vocational Colleges), 7(1), 47-53.

60. TS EN 310 (1999). Ahşap esaslı levhalar-Eğilme dayanımı ve eğilme elastikiyet modülünün tayini, Türkiye Standartlar Enstitüsü (TSE), Ankara.

61. TS EN 312 (2012). Yonga levhalar - Özellikler, Türkiye Standartlar Enstitüsü (TSE), Ankara.

62. TS EN 317 (1999). Yonga levhalar ve lif levhalar-Su içerisine daldırma işleminden sonra kalınlığına şişme tayini, Türkiye Standartlar Enstitüsü (TSE), Ankara. 
63. TS EN 319 (1999). Yonga levhalar ve lif levhalar-Levha yüzeyine dik çekme dayanımının tayini, Türkiye Standartlar Enstitüsü (TSE), Ankara.

64. TS EN 322 (1999). Ahşap esaslı levhalar-Rutubet miktarının tayini, Türkiye Standartlar Enstitüsü (TSE), Ankara.

65. TS EN 323 (1999). Ahşap esaslı levhalar-Birim hacim ağırlığının tayini, Türkiye Standartlar Enstitüsü (TSE), Ankara.

66. TS EN 326 (1999). Ahşap esaslı levhalar-Numune alma kesme ve muayene bölüm 1:Deney numunelerinin seçimi, kesimi ve deney sonuçlarının gösterilmesi, Türkiye Standartlar Enstitüsü (TSE), Ankara.

67. Valarelli, I. D. D., Battistelle, R. A., Bueno, M. A. P., Bezerra, B. S., Campos, C. I. D., Alves, M. C. D. S. (2014). Physical and mechanical properties of particleboard bamboo waste bonded with urea formaldehyde and castor oil based adhesive. Matéria (Rio de Janeiro), 19(1), 1-6.

68. Xu, J., Han, G., Kawai, S. (2003). Development of binderless particleboard from kenaf core using steaminjection pressing. Journal of wood science, 49(4), 327-332.

69. Xu, X., Yao, F., Wu, Q., Zhou, D. (2009). "The influence of wax-sizing on dimension stability and mechanical properties of bagasse particleboard," Industrial crops and products 29(1), 80-85.

70. Youngquist, J. A. (1999). Wood-based composites and panel products, Wood handbook: wood as an engineering material. Madison, WI: USDA Forest Service, Forest Products Laboratory, 1999. General technical report FPL; GTR-113: Pages 10.1-10.31, 113. 